\title{
Religiosidad popular en las Conferencias Episcopales Latinoamericanas y en el Magisterio de Francisco
}

\author{
Popular religiousness in the Latin American Episcopal Conferences and in the \\ Francisco Magisterium
}

\author{
María del Pilar Silveira \\ Doctora en Teología \\ Profesora, International Fellowship Initiative \\ at Boston College School of Theology and Ministry \\ mpilarsilveira@gmail.com \\ Fecha de recepción: 30-07-2019 \\ Fecha de aceptación: 28-10-2019
}

Como citar este artículo: M. SILVEIRA. "Religiosidad popular en las Conferencias Episcopales Latinoamericanas y en el Magisterio de Francisco" en Palabra y Razón. Revista de Teología, Filosofía y Ciencias de la Religión N$^{\circ} 16$, Diciembre 2019, pp. 81-94 https://doi.org/10.29035/pyr.16.81

Resumen: En el presente artículo haré una descripción de la religiosidad popular latinoamericana, destacando su abordaje en el Magisterio de la Iglesia y en las Conferencias Episcopales desde Medellín hasta Aparecida. Me detendré en el Magisterio del Papa Francisco, especialmente en los lineamientos que aparecen en Evangelii Gaudium referidos al tema. La misma línea teológica del Cardenal Bergoglio que fue Presidente de la Comisión de redacción del Documento final de Aparecida, se observa en su Magisterio basado en la teología del pueblo. Aparecida, santuario mariano, marcó una línea teológica, que podemos percibir como el tiempo de María, porque el mismo lugar físico, fue un signo para resaltar y sacar del anonimato la fe popular mariana que silenciosamente ha crecido y sigue propagándose, evangelizándose a sí misma de manera muy creativa ${ }^{1}$. El Papa ha captado esta acción silenciosa en el corazón de la gente que ama y sigue a la Madre de Dios más allá de las estructuras eclesiales y de la institución eclesial. Es un desafío que pone a la iglesia en movimiento, rompiendo paradigmas y abriendo puertas, para que el Espíritu se haga carne en los más desprotegidos y débiles que solo tienen a la Madre del Salvador como esperanza. Pensemos en los miles de fieles que acuden a los santuarios pidiendo salud, paz, trabajo, comida... en un continente que sigue preso en estructuras que producen más desfavorecidos cada día.

Palabras clave: religiosidad popular, piedad popular, espiritualidad popular, mariología popular, teología del pueblo.

\footnotetext{
${ }^{1}$ M. P. SILVEIRA. Mariología popular Latinoamericana. Fisonomía de la Mariología popular venezolana. UCAB-Arquidiócesis de Mérida: Caracas, 2013.
} 
Abstract: In this article I will give a description of Latin American popular religiosity, highlighting its approach in the Magisterium of the Church and in the Episcopal Conferences from Medellin to Aparecida. I will work off of the Magisterium of Pope Francis, especially from the guidelines that appear in Evangelii Gaudium on the topic. The same theological line of Cardinal Bergoglio, who was the Chairman of the Committee for the Drafting of the Final Document of Aparecida, is observed in his Magisterium based on the theology of the people. The Marian shrine of Aparecida marks a theological line, which we can perceive as the time of Mary. That place is a sign to highlight and remove from the anonymity of the Marian popular faith that has quietly grown and continues to spread, evangelizing itself in a very creative way. The Pope has captured this silent action in the hearts of the people who love and follow the Mother of God beyond the ecclesial structures and the ecclesial institution. It is a challenge that sets the church in motion, breaking paradigms and opening doors, so that the Spirit may become flesh in the most unprotected and weakest that only have the Savior's Mother as hope. Let us think of the thousands of faithful who come to the shrines asking for health, peace, work, food... on a continent that remains imprisoned in structures that produce more disadvantaged every day.

Keywords: popular religiosity, popular piety, popular spirituality, popular mariology, people's theology.

\section{Introducción}

La religiosidad popular surge desde los comienzos del cristianismo y ha contribuido a la elaboración teológica de la Iglesia, pues la experiencia de fe vivida por las comunidades cristianas en su vida cotidiana, ha sido la base de la reflexión teológica eclesial. En América Latina y el Caribe, es una de las riquezas más fuertes y sólidas que poseen nuestros pueblos de vivir su fe y expresarla ricamente en medio de su cultura desde los primeros tiempos del encuentro entre la diversidad de culturas amerindias y la española. A través de la evangelización de los misioneros que predicaban la Palabra de Dios y de las imágenes de Jesús y de la Virgen María, la fe católica se fue haciendo carne en la vida cotidiana, dando rostro al ethos cultural de los pueblos que fueron creados y bautizados con nombres cristianos. Según el cardenal Bergoglio: "la doctrina que trajeron los misioneros se sincretizó con formas africanas o indígenas, y dando lugar en algunos casos a formas mixtas muy bien integradas"2. El mestizaje de las razas, es una muestra de nuestra "originalidad histórica cultural"3, a la que se refiere el DP 446 diciendo que "esa identidad se simboliza muy luminosamente en el rostro mestizo de María de Guadalupe que se yergue al inicio de la Evangelización". Podemos decir que la religiosidad popular se encuentra en el alma de nuestros pueblos y es lugar de encuentro con Jesús. Su acompañamiento, acogida y servicio pastoral, ha tenido y tiene incluso hoy, muy diversos niveles.

\footnotetext{
${ }^{2}$ Cfr. J. BERGOGLIO Cardenal, S.J. Religiosidad popular como inculturación de la fe en el Espíritu de Aparecida, 14 de enero de 2008, 16, disponible en https://www.arzbaires.org.ar/inicio/homilias/ homilias2008.htm\#cultura_y_Religiosidad_popular

${ }^{3}$ Expresión que se cita en DA 264, que se refiere a DP 446 y no erróneamente a DP 448 como lo indica la cita a pie de página.
} 


\section{Definición de términos}

Existen muchas maneras de describir la religiosidad popular, comenzaré por el término religión, del latín, re-ligare, que es la relación entre el ser humano y la trascendencia, pues la religión es una manera de sentirse referido a lo sagrado (a Dios, y en general al mundo de lo divino) y al modo como se expresa en la práctica esta conciencia de estar referidos a dicha realidad ${ }^{4}$. La "fe popular," es la manifestación o expresión de la fe religiosa de un grupo de personas en acontecimientos que les identifica como pueblo y se expresa en una cultura. ¿Cómo se manifiesta la fe popular? se hace visible en la religiosidad popular, que es la actuación popular de la religión cristiana es decir, la fe vivida, expresada a través de la cultura del pueblo. Para Bergoglio: "es simplemente la religiosidad de la gente creyente que no puede menos que expresar públicamente, con sincera y sencilla espontaneidad, su fe cristiana, recibida de generación en generación, y que ha ido configurando la vida y las costumbres de todo su pueblo"s.

A esta definición agregó el carácter universal que acentúa el Directorio de Piedad Popular y Liturgia al destacar que "la religiosidad popular, se refiere a una experiencia universal: en el corazón de toda persona, como en la cultura de todo pueblo y en sus manifestaciones colectivas, está siempre presente una dimensión religiosa" $"$.

Es importante destacar que la fe popular se hace vida en lo que se puede llamar "piedad popular," que es lo "escondido", lo que no se ve y está detrás de las devociones, es decir la vida, la energía que mueve la fe en las distintas devociones. Piedad y religiosidad son dos aspectos de un mismo rostro, que no se pueden separar, pero se distinguen aunque hay que integrarlos y unirlos en una relación dinámica. La religiosidad o religión popular es la manifestación, en gestos, comportamientos; la piedad popular es lo escondido, el humus, la matriz, la fuente interior de esos hechos exteriores. Por lo tanto no se puede descuidar ese animus, ese corazón íntimo porque lleva a reducir las expresiones de la religiosidad popular a descripciones sociales o psicológicas. La misma expresa su experiencia religiosa en símbolos e historias míticas y se mueve en el conocimiento del sentido común y del drama. El sentido común se concibe como la acumulación espontánea de intelecciones relacionadas en

\footnotetext{
${ }^{4}$ Cfr. L. DANI. Religión en Diccionario de Sociología. Ediciones Paulinas: Madrid, 1986, p. 1466.

${ }^{5}$ Cfr. J. BERGOGLIO Cardenal, S.J. Religiosidad popular como inculturación de la fe en el Espíritu de Aparecida, 15.

${ }^{6}$ Cfr. CONGREGACIÓN PARA EL CULTO DIVINO Y LA DISCIPLINA DE LOS SACRAMENTOS. Directorio sobre la piedad popular y la liturgia. Principios y orientaciones, Ciudad del Vaticano 2002, $\mathrm{n}^{\circ}$ 10, disponible en: http://www.vatican.va/roman_curia/congregations/ccdds/documents/rc_con ccdds_doc_20020513_vers-direttorio_sp.html
} 
el campo de lo particular y concreto y su argumento es la analogía ${ }^{7}$. Para su adecuada comprensión, se requiere de un estudio multidisciplinar con el aporte de ciencias y disciplinas como la historia, la antropología, la sociología, la teología, la filosofía, la psicología entre otras.

Pablo VI en Evangelii Nuntiandi 48, reconoce atributos y situaciones que alertan a la iglesia para que no caiga en desviaciones.

La religiosidad popular, hay que confesarlo, tiene ciertamente sus límites. Está expuesta frecuentemente a muchas deformaciones de la religión, es decir, a las supersticiones. Se queda frecuentemente a un nivel de manifestaciones culturales, sin llegar a una verdadera adhesión de fe. Puede incluso conducir a la formación de sectas y poner en peligro la verdadera comunidad eclesial.

Pablo VI continua afirmando que cuando

está bien orientada, sobre todo mediante una pedagogía de evangelización, contiene muchos valores. Refleja una sed de Dios que solamente los pobres y sencillos pueden conocer. Hace capaz de generosidad y sacrificio hasta el heroísmo, cuando se trata de manifestar la fe. Comporta un hondo sentido de los atributos profundos de Dios: la paternidad, la providencia, la presencia amorosa y constante. Engendra actitudes interiores que raramente pueden observarse en el mismo grado en quienes no poseen esa religiosidad: paciencia, sentido de la cruz en la vida cotidiana, desapego, aceptación de los demás, devoción. Teniendo en cuenta esos aspectos, la llamamos gustosamente "piedad popular", es decir, religión del pueblo, más bien que religiosidad ${ }^{8}$.

Francisco seguirá estos lineamientos de Pablo VI y siendo cardenal afirma que "revalorizar la religiosidad popular es revalorizar el propio pasado de la iglesia como también su continuidad histórica entre los hombres del pueblo latinoamericano".

La historia se ha encargado de poner en evidencia su valor e importancia, demostrando que muchas veces la religiosidad de los pobres es el camino utilizado por el Espíritu para llegar al corazón de los creyentes y atraerlos a la vida de fe ${ }^{10}$. Por lo cual es importante para comprender su complejidad seguir una metodología adecuada que no desvirtúe su riqueza original y descubra la presencia del Espíritu de Dios que obra en el corazón de los fieles.

\footnotetext{
${ }^{7}$ Cfr. B. LONERGAN. Insight. Estudio sobre la comprensión humana. Ed. Sígueme: Salamanca, 1999, pp. 223-304.

${ }^{8} \mathrm{EN} 48$.

${ }^{9}$ Cfr. BERGOGLIO, J. Cardenal, S.J. Religiosidad popular como inculturación de la fe en el Espíritu de Aparecida, 15.

${ }^{10}$ Cfr. CELAM. Testigos de Aparecida. Vol. II. ediciones del CELAM: Bogotá, 2008, pp. 308-325.
} 


\section{Acercamiento a la comprensión de la religiosidad popular en América Latina}

La comprensión sobre el contenido e importancia de la religiosidad popular fue creciendo en la reflexión eclesial latinoamericana. El Concilio Plenario Latinoamericano (1899), reconoce las características religiosas del pueblo que se expresaba en diversas prácticas, tales como el culto a las imágenes, reliquias, peregrinaciones, devociones, entre otras, aceptándolas como "expresiones naturales de la fe del pueblo."

En la Conferencia de Rio de Janeiro (1955), los obispos aprecian "el don de la fe católica que la consideran un patrimonio común de las naciones que es preciso acrecentar para que integre el pensamiento, las costumbres y las instituciones de nuestro Continente" ${ }^{11}$. Lo describen diciendo que es un inmenso continente que se "enorgullece de su fe católica", y es una magnífica esperanza para toda la Iglesia de Cristo (2.a). Advierten la presencia de movimientos anticatólicos que tienden a acrecentarse por la falta de clero (2.b). Proponen la formación de los laicos para combatir las creencias contrarias a la fe católica: el espiritismo y el mandamiento divino que prohíbe las supersticiones, la magia y la invocación de los muertos y de los espíritus" (75.1). También agregan la masonería, las sectas y el folklore con prácticas supersticiosas $(76.1$ al 78) como manifestaciones que atentan contra la integridad de la fe católica. La propuesta formativa de la Acción Católica bajo la guía del clero hacia los laicos, la juventud, se hizo con la esperanza de consolidar una doctrina católica basada en la moral y en las buenas costumbres.

El período comprendido desde 1960 a 1980 fue muy fecundo tanto en los cambios sociales como en la elaboración de diferentes interpretaciones sobre el hecho religioso que enriquecieron la conciencia eclesial para un abordaje más preciso ${ }^{12}$. El énfasis pastoral se orientó a promover una pastoral de élites menospreciando a la piedad popular pues se cuestionó su "incapacidad" para animar el proceso de búsqueda de estructuras más justas para la sociedad.

\footnotetext{
${ }^{11}$ Cfr. Documento Conclusivo de Rio de Janeiro, 1, 1955.

12 Según la investigación de Neira, Germán. Tres líneas de interpretación (1960-1980). Bogotá: Pontificia Universidad Javeriana, 2007. Idem., Religión popular católica latinoamericana. Dialéctica de interpretaciones (1960-1980). Bogotá: Pontificia Universidad Javeriana, 2007; existen tres líneas de interpretación de la religión popular: la línea de la modernización, la del cambio social justo y la línea cultural. Los autores que se destacan en la investigación académica sobre la religiosidad popular son: Cristián Johansson, teólogo chileno, Gilberto Jiménez, sociólogo paraguayo, Manuel Marzal, antropólogo peruano, Segundo Galilea, teólogo chileno, Diego Irarrázaval, teólogo chileno, José Comblin, teólogo belga profesor de la Pontificia Universidad Católica de Chile, Juan Carlos Scannone, teólogo argentino, Lucio Gera, teólogo argentino, Enrique Dussel, filósofo argentino, Carlos María Galli, teólogo argentino, Alberto Methol, historiador uruguayo, José Alliende, teólogo, entre otros. La mayoría de estos autores analizan la religiosidad popular desde la teología de la liberación, descubriendo en ella el sentido liberador de la praxis humana.
} 


\section{Los balbuceos de una auténtica religiosidad que contiene frutos del Evangelio}

El Documento Conclusivo de la II Conferencia realizada en Medellín (1968), parte del análisis de la realidad de los pueblos latinoamericanos incorporando la sugerencia de que la iglesia se adapte a las diversas culturas en su misión evangelizadora propuesta por el Concilio Vaticano II (AG 9) y una reflexión de teólogos latinoamericanos sobre la pastoral popular y la religiosidad popular. En la perspectiva de una nueva evangelización y de una opción por los pobres, se reconocen las características culturales particulares de cada pueblo para adaptar la catequesis, la pastoral popular y la liturgia. "Hoy, sin embargo, las mismas transformaciones del continente exigen una revisión de esa pastoral, a fin de que se adapte a la diversidad y pluralidad culturales del pueblo"13. Para hacer esa revisión se sigue el criterio de que "[...] todo lo bueno que se halla sembrado en el corazón y en la mente de los hombres, en los propios ritos y en las culturas de los pueblos, no solamente no perece, sino que es purificado, elevado y consumado para gloria de Dios, confusión del demonio y felicidad del hombre" (AG 9). Se define de esta manera: "Es una religiosidad de votos y promesas, de peregrinaciones y de un sinnúmero de devociones, basada en la recepción de los sacramentos, especialmente del bautismo y de la primera comunión, recepción que tiene más bien repercusiones sociales que un verdadero influjo en el ejercicio de la vida cristiana" ${ }^{14}$. Valora la reserva de virtudes auténticas cristianas tales como "la caridad, aún cuando muestre deficiencias su conducta moral. Su participación en la vida cultual oficial es casi nula y su adhesión a la organización de la Iglesia es muy escasa" ${ }^{15}$. Sobre el significado de la participación la reflexión teológica seguirá avanzando comprendiendo en los signos y en las expresiones populares el sentido popular de ser parte de la iglesia, especialmente a través de la devoción mariana ${ }^{16}$. El dilema principal de la incomprensión o enjuiciamiento apresurado a la religiosidad popular es que se convierta en secta o que se diluya en un sincretismo religioso. Afirma que es importante discernir y estar atentos a las manifestaciones religiosas que pueden ser "balbuceos de una auténtica religiosidad expresada con elementos culturales". No perdiendo de vista que "la fe llega al hombre envuelta siempre en un lenguaje cultual y por eso en la religiosidad natural pueden encontrarse gérmenes de un llamado de Dios" ${ }^{17}$. El aporte del Documento de Medellín fue muy importante para las iglesias particulares que tomaron estos lineamientos y los aplicaron en sus planes pastorales, continuando la reflexión teológica en los institutos

\footnotetext{
${ }^{13}$ DM. VI Pastoral Popular, p. 1.

${ }^{14}$ DM. VI Pastoral Popular, p. 2.

${ }^{15}$ DM. VI Pastoral Popular, p. 1.

${ }^{16}$ Cfr. M.P. SILVEIRA. Mariología popular Latinoamericana..., p. 302, 303. Analiza en base a una investigación en santuarios venezolanos sobre la pregunta ¿participas en la iglesia? La respuesta final fue afirmativa, y el análisis se basó en los hechos que manifiestan sentimientos de participación simbólica y afectica según las categorías empleadas por el teólogo Lucio Gera.

${ }^{17}$ Cfr. DM. VI Pastoral Popular, p. 4.
} 
y facultades de teología de los diversos países ${ }^{18}$. En Argentina el Documento de San Miguel (1969) ${ }^{19}$ es el fruto de la aplicación de DM y las situaciones de violencia y de gobiernos dictatoriales retaron a las iglesias particulares a responder desde una fe hecha carne en una sociedad politizada, dividida, donde los criterios evangélicos eran cuestionados. ¿Es posible ser cristiano y marxista? ¿Podemos responder a esta realidad de abusos de poder desde una justa rebelión, o seguimos el mandamiento de no matar, la no violencia con la consecuencia del martirio? Este tipo de preguntas realizadas a los sacerdotes que estaban viviendo en poblaciones campesinas, insertos en zona populares, tuvieron que dar una respuesta a sus fieles, muchos de ellos catequistas, asiduos a la parroquia y comprometidos en una situación de guerrilla armada en gobiernos de dictaduras cruentas como El Salvador. La fe sencilla de los católicos latinoamericanos víctimas de la pobreza y de sistemas políticos injustos especialmente destaco a la mayoría de mujeres, comunicadoras a sus hijos y nietos de una fe viva, manifestada en expresiones de amor a las imágenes de Jesús, de María y de otros santos, fue la que cuestionó a los teólogos latinoamericanos a buscar respuestas desde una fe liberadora y no opresora, que lograra la humanización y la fraternidad.

En 1974 se realizó en Roma un Sínodo sobre la evangelización en el mundo moderno en el cual participó Mons. Pironio quien recibió el aporte del Celam sobre la teología de la religiosidad popular. Este Sínodo es el preámbulo para la Exhortación Apostólica Evangelii Nuntiandi (1975) en la que describe la religiosidad popular dentro del concepto de piedad popular (EN 48).

La III Conferencia Episcopal en Puebla (1979) recoge los aportes que se hicieron desde DM, con sus críticas y sus avances teológicos que enriquecieron el DP ${ }^{20}$ ponderando la religiosidad popular y destacando que contiene "frutos del evangelio" que son una fuerza activamente evangelizadora. El mismo pueblo se evangeliza a sí mismo: "La religiosidad popular no solamente es objeto de evangelización, sino que, en cuanto contiene encarnada la Palabra de Dios, es una forma activa con la cual el pueblo se evangeliza continuamente a sí mismo (DP 450). Y luego de dar orientaciones para la acción pastoral, los obispos concluyen con una aseveración que tiene vigencia en la actualidad:

\footnotetext{
${ }^{18}$ V.M. FERNÁNDEZ. Con los pobres hasta el fondo: el pensamiento teológico de Rafael Tello. Revista Proyecto, n.36, p. 201, 2000. El autor describe el aporte del padre Rafael Tello a la teología de la cultura popular.

${ }^{19}$ Cfr. E. C. BIANCHI. "El tesoro escondido de Aparecida: la espiritualidad popular". Revista Teología, n. 100 , pp. 563 ss. El documento se refiere a la pastoral popular que es la acción de la iglesia que busca evangelizar al pueblo desde el pueblo mismo, es decir que el pueblo es sujeto y agente de la historia. La religiosidad popular es un elemento de la cultura del pueblo pero "el concepto de pueblo recoge y supera al de la cultura, a la vez que la hace más dinámica no estática." Dentro del equipo de peritos sobre el tema de pastoral popular se destaca el teólogo Lucio Gera.

${ }^{20}$ DP. 3 evangelización y religiosidad popular, 444 al 469.
} 
Si la Iglesia no reinterpreta la religión del pueblo latinoamericano, se producirá un vacío que lo ocuparán las sectas, los mesianismos políticos secularizados, el consumismo que produce hastío y la indiferencia o el pansexualismo pagano. Nuevamente la Iglesia se enfrenta con el problema: lo que no asume en Cristo, no es redimido y se constituye en un ídolo nuevo con malicia vieja ${ }^{21}$.

La IV Conferencia del Episcopado Latinoamericano de Santo Domingo (1992), describe el concepto de religiosidad popular como una "forma inculturada del catolicismo" (DSD 247) y nos ofrece elementos novedosos relacionados con el tema.

\section{El precioso tesoro de la Iglesia católica: espiritualidad popular encarnada}

La V Conferencia celebrada en Aparecida (2007), tuvo la particularidad de que se realizó en un santuario mariano ${ }^{22}$, en un ambiente de oración, así lo señala el DA 3: "nos hemos sentido acompañados por la oración de nuestro pueblo creyente católico." El Cardenal Bergoglio luego de la Conferencia expresó: "nuestra música funcional eran las oraciones y las misas que se celebraban con nuestro pueblo"23. Los "balbuceos de una auténtica religiosidad" a los que se refirió el DM fueron escuchados e interpretados por la Comisión de redacción ${ }^{24}$ y se recogieron en el apartado 6.1.3 "La piedad popular como espacio de encuentro con Jesucristo". Allí se encuentra una descripción detallada, con un lenguaje sencillo y hasta poético de las diversas expresiones religiosas del pueblo (DA 258-265). Es un relato del hecho religioso que acontece cada día en ese santuario mariano. En la hermenéutica del "el precioso tesoro de la Iglesia Católica en América Latina" ${ }^{25}$, se aprecia la influencia de la teología del pueblo representada en el teólogo Carlos María Galli26.

La novedad del DA es llamar "espiritualidad popular" al modo de vivir la fe de una manera auténtica, este término junto al de piedad popular es usado con más frecuencia y su ubicación como punto de partida para su maduración y crecimiento es del Directorio de la Piedad Popular y la Liturgia (2002) ${ }^{27}$. Se menciona una vez la

\footnotetext{
${ }^{21}$ DP. 3 evangelización y religiosidad popular, 469.

${ }^{22}$ El Santuario nacional de Aparecida recibe cada semana aproximadamente unos 150.000 peregrinos, lo que produce un permanente flujo de personas por toda la basílica.

${ }^{23}$ M. BERGOGLIO. Entrevista al cardenal Jorge Mario, arzobispo de Buenos Aires, en: 30 Giorni, n.11, XXV, 2007, 20.

${ }^{24}$ Dentro de los peritos de la comisión de redacción se encontraba Carlos María Galli que sigue la línea teológica del Pbro. Lucio Gera y Rafael Tello de la teología del pueblo argentina.

${ }^{25}$ DI 1.

${ }^{26}$ Cfr. E. C. BIANCHI. "El tesoro escondido de Aparecida...”, pp. 557-577.

${ }^{27}$ JUAN PABLO II. Directorio sobre la piedad popular y la liturgia. Principios y Orientaciones. Roma: Tipografía Vaticana, 2002.
} 
expresión "mística popular"28 (DA 262) para referirse a la experiencia profunda de un misterio que supera e invita a la conversión y a tomar decisiones que marcan la vida de las personas (DA 260). Porque en

la piedad popular, se contiene y expresa un intenso sentido de la trascendencia, una capacidad espontánea de apoyarse en Dios y una verdadera experiencia de amor teologal. Es también una expresión de sabiduría sobrenatural, porque la sabiduría del amor no depende directamente de la ilustración de la mente sino de la acción interna de la gracia. Por eso, la llamamos espiritualidad popular ${ }^{29}$.

Agrega también que es "un encuentro personal con el Señor, integra mucho lo corpóreo, lo sensible, lo simbólico, y las necesidades más concretas de las personas. Es una espiritualidad encarnada en la cultura de los sencillos, que, no por eso, es menos espiritual, sino que lo es de otra manera. En el numeral 264 se destaca el modo de sentirse parte de la iglesia, porque es una fe legítima. Si bien se menciona la necesidad de purificación lo hace en el sentido de hacer crecer las riquezas presentes en el pueblo:

Cuando afirmamos que hay que evangelizarla o purificarla, no queremos decir que esté privada de riqueza evangélica. Simplemente deseamos que todos los miembros del pueblo fiel, reconociendo el testimonio de María y también de los santos, traten de imitarles cada día más ${ }^{30}$.

Es importante destacar dentro del apartado 6.1.3, el lugar privilegiado que tiene la piedad mariana en la espiritualidad popular enriqueciendo la mariología popular que es la manera como el pueblo vive su fe y amor a la Virgen María haciendo vida lo que ha recibido a través de la formación católica y el lugar que tiene María en el conjunto de la religión del pueblo. Se expresa en diversas manifestaciones tales como peregrinaciones, novenas, rezo del rosario, como tantas otras en las que el pueblo manifiesta su amor a la madre.

En distintos momentos de la lucha cotidiana, muchos recurren a algún pequeño signo del amor de Dios: un crucifijo, un rosario, una vela que se enciende para acompañar a un hijo en su enfermedad, un Padrenuestro musitado entre lágrimas, una mirada entrañable a una imagen querida de María, una sonrisa dirigida al Cielo, en medio de una sencilla alegría ${ }^{31}$.

\footnotetext{
${ }^{28}$ Cfr. J. SEIBOLD. La mística popular, Buena Prensa, México, 2006. Texto citado por Bianchi, "El tesoro escondido de Aparecida...”, p. 571.

${ }^{29}$ Cfr. DA 263.

${ }^{30} \mathrm{Cfr}$. DA 262.

${ }^{31}$ DA 261.
} 
En el rostro de María "encuentran la ternura y el amor de Dios y ven reflejado el mensaje esencial del Evangelio" (DA 265). Este amor a la Virgen "ha sido capaz de fundir las historias latinoamericanas diversas en una historia compartida" (DA 43). En esas expresiones está la presencia del Espíritu de Dios que es el que moviliza el corazón del creyente y el que propicia la "fides quaerens intellectum". En este sentido es importante valorar sin subestimar los gestos y las palabras de veneración y alabanza de las personas a la Virgen. Son expresiones de la fe de cada individuo, no menos que del colectivo social, que se transmiten a los demás y se socializan, por acciones de culto popular, tales como el rezo del Rosario, el prender velas, el pagar promesas, el imponerse sacrificios. Por lo cual se afirma que la religión del pueblo contiene mucha riqueza teológica y cultural que requiere de una hermenéutica apropiada para su interpretación que tenga en cuenta el sentido común. Ese modo peculiar de pensar y vivir lo cristiano mariano es un aporte de nuestros pueblos a la búsqueda actual de la Iglesia ${ }^{32}$.

\section{Manifestación de una vida teologal espontánea animada por la acción del Espíritu Santo}

El Papa Francisco en la Exhortación Apostólica Evagengelii Gaudium (EG) orientada hacia la evangelización, cuando hace referencia a la piedad popular (EG 69,70, 22 a 126) sigue los lineamientos del DA y la definición de EN de Paulo VI: "refleja una sed de Dios que solamente los pobres y sencillos pueden conocer" 33 . Francisco exhorta a la imperiosa necesidad de evangelizar las culturas donde se encuentra la piedad popular. "Es vital que hoy la Iglesia salga a anunciar el Evangelio a todos, en todos los lugares, en todas las ocasiones, sin demoras, sin asco y sin miedo" ${ }^{34}$. En el proceso de inculturación del Evangelio, "que tiene un potencial que no se puede predecir, que supera nuestras previsiones y rompe esquemas ${ }^{35}$, el pueblo tiene una activa tarea pues se evangeliza a sí mismo al traducir en su vida el don de Dios según su genio propio. "Aquí toma importancia la piedad popular, verdadera expresión de la acción misionera espontánea del Pueblo de Dios. Se trata de una realidad en permanente desarrollo, donde el Espíritu Santo es el agente principal (EG 122). Si bien aclara que "toda cultura y todo grupo social necesita purificación y maduración", hace un llamado a su crecimiento. Enumera algunas debilidades que necesitan ser sanadas por el Evangelio: el machismo, el alcoholismo, la

\footnotetext{
${ }^{32}$ Cfr. S. GALILEA. "Análisis empírico de la religiosidad latinoamericana, (1969)”. En Catolicismo popular. A. Büntig et al. IPLA: Quito, 1979. S. GALILEA. religiosidad popular y pastoral. Ediciones Cristiandad: Madrid, 1979, 327; P. RIBEIRO DE OLIVEIRA. O Catolicismo do Povo. In: Evangelização e comportamento religioso popular. Cadernos de Teologia e pastoral No. 8. Petrópolis: Vozes, 1978.

${ }^{33} \mathrm{EN} \mathrm{48,} \mathrm{AAS} 68$ (1976), 38.

${ }^{34} \mathrm{Cfr}$. EG 23.

${ }^{35} \mathrm{Cfr}$. EG 22.
} 
violencia doméstica, una escasa participación en la Eucaristía, creencias fatalistas o supersticiosas que hacen recurrir a la brujería, etc. Pero afirma que "es precisamente la piedad popular el mejor punto de partida para sanarlas y liberarlas" ${ }^{36}$. Invita a un discernimiento de las prácticas devocionales cristianas que se absolutizan y llevan al individualismo. Y previene sobre la ruptura en la transmisión generacional de la fe cristiana en el pueblo católico que viene aumentando en las últimas décadas ${ }^{37}$. $\mathrm{Su}$ propuesta sobre la manera de abordar al pueblo es con la caridad pastoral del Buen Pastor (cfr. EG 125) que primerea, se involucra, acompaña, fructifica y festeja, "tocando la carne sufriente de Cristo en el pueblo, e impregnándose de "olor a oveja" ${ }^{38}$. Pretende que la Iglesia sea el lugar de la misericordia gratuita, donde todo el mundo pueda sentirse acogido, amado, perdonado y alentado a vivir según la vida buena del Evangelio" 39 . Una iglesia Pueblo de Dios que se encarna en cada uno de los pueblos de la tierra que tiene su propia cultura desplegando la belleza de un rostro pluriforme ${ }^{40}$. Es una madre de corazón abierto y casa siempre abierta para todos ${ }^{41}$.

Siguiendo los lineamientos del DA en EG 124 utiliza los mismos términos para referirse a la piedad popular: espiritualidad popular encarnada en la piedad de los sencillos, mística popular, legitimando el acto de fe popular donde se destaca la mariología popular. "El caminar juntos hacia los santuarios y el participar en otras manifestaciones de la piedad popular, también llevando a los hijos o invitando a otros, es en sí mismo un gesto evangelizador. ¡No coartemos ni pretendamos controlar esa fuerza misionera!"’2 Implícitamente en esta expresión se menciona el papel de la mujer en la piedad popular que en el siguiente numeral destaca:

Sólo desde la connaturalidad afectiva que da el amor podemos apreciar la vida teologal presente en la piedad de los pueblos cristianos, especialmente en sus pobres. Pienso en la fe firme de esas madres al pie del lecho del hijo enfermo que se aferran a un rosario aunque no sepan hilvanar las proposiciones del Credo, o en tanta carga de esperanza derramada en una vela que se enciende en un humilde hogar para pedir ayuda a María, o en esas miradas de amor entrañable al Cristo crucificado. Quien ama al santo Pueblo fiel de Dios no puede ver estas acciones sólo como una búsqueda natural de la divinidad. Son la manifestación de una vida teologal animada por la acción del Espíritu Santo que ha sido derramado en nuestros corazones (cf. Rm 5,5) ${ }^{43}$.

\footnotetext{
${ }^{36}$ Cfr. EG 69.

${ }^{37}$ Cfr. EG 70.

${ }^{38} \mathrm{Cfr}$. EG 24.

${ }^{39}$ Cfr EG 114.

${ }^{40} \mathrm{Cfr}$. EG 116.

${ }^{41} \mathrm{Cfr}$. EG, apartado V Una madre de corazón abierto.

${ }^{42}$ Cfr. EG 124.

${ }^{43}$ Cfr. EG 125.
} 
La fe popular contiene la presencia silenciosa del Espíritu el sensus fidei que le otorga a los cristianos una cierta familiaridad con las realidades divinas y una sabiduría para captarlas intuitivamente, aunque no encuentre palabras para explicar su $\mathrm{fe}^{44}$. Teniendo en cuenta esa sabiduría silenciosa que es fruto del Espíritu, Francisco en el numeral 126, invita a prestar atención y a no ser indiferentes ante las expresiones de piedad popular que define como un lugar teológico, que hay que saber interpretar en la nueva evangelización. Al catalogar como lugar teológico a la piedad popular, está valorando su riqueza pedagógica, obra inacabada del Espíritu que necesita ser interpretada correctamente. En pocas palabras invita a los agentes pastorales a estar atentos a las diversas expresiones de piedad popular, y a formarse con los conocimientos adecuadas para leer su simbología.

En la piedad popular, por ser fruto del Evangelio inculturado, subyace una fuerza activamente evangelizadora que no podemos menospreciar: sería desconocer la obra del Espíritu Santo. Más bien estamos llamados a alentarla y fortalecerla para profundizar el proceso de inculturación que es una realidad nunca acabada. Las expresiones de la piedad popular tienen mucho que enseñarnos y, para quien sabe leerlas, son un lugar teológico al que debemos prestar atención, particularmente a la hora de pensar la nueva evangelización ${ }^{45}$.

En la figura de María, santuario del Espíritu Santo, madre de todos, el Papa concluye la Exhortación reconociendo que "hay un estilo mariano en la actividad evangelizadora de la Iglesia. Porque "cada vez que miramos a María volvemos a creer en lo revolucionario de la ternura y del cariño. En ella vemos que la humildad y la ternura no son virtudes de los débiles sino de los fuertes, que no necesitan maltratar a otros para sentirse importantes" ${ }^{\prime 4}$. Podemos decir que la actividad evangelizadora de la Virgen que atrae por convicción como se observa en los santuarios marianos, nos lleva a observar en silencio la acción de Dios que siempre supera nuestras expectativas y planes organizados para ponernos en movimiento y continuar el camino de la fe.

\section{Conclusión}

He descrito en forma sintética el camino recorrido durante más de cuarenta años de la religiosidad popular en el magisterio latinoamericano. Un trayecto con períodos de aceptación y de rechazo del precioso tesoro que hoy resplandece en el magisterio papal. Nuestros pueblos siguen sufriendo el flagelo de la pobreza, ¿qué

\footnotetext{
${ }^{44}$ Crf. EG 119.

${ }^{45}$ Cfr. EG 126.

${ }^{46}$ Cfr. EG 288.
} 
sucede que no es posible lograr cambios profundos, radicales, fruto de la conversión al Dios de Jesucristo construyendo una fraternidad solidaria, con los bienes necesarios para vivir? Aparentemente las ofertas de una vida nueva basada en el tener y las ideologías que ponen en primer lugar el capital por encima de la persona, son los principios que adormecen la conciencia de un continente globalizado.

Si bien la religiosidad popular contiene una fuerza vital que se observa en la expresión de la fe, pues las personas se sienten sujetos activos en las peregrinaciones, las fiestas, sintiéndose en los santuarios como en su casa junto a la Madre; luego al compartir esta fe y al socializarla, ¿qué sucede? Aparentemente el tesoro sigue escondido, falta compartirlo, socializarlo, organizarlo para lograr objetivos claros. Falta dar argumentos, conciencia para que se oriente esta fuerza vital hacia una humanización, donde la persona asuma que es sujeto de su vida, que tiene el poder de cambiar y que esta fuerza no está fuera de ella, en las autoridades eclesiales revestidas por la fuerza del Espíritu, o en los gobernantes que prometen soluciones. Los sujetos son los que saben que tienen en sus manos el poder de construir la historia, son artífices de su propio destino, pues el Espíritu de Dios los habita. Ese mismo Espíritu que nos hermana, que nos hace vernos a los ojos desde el mismo nivel, y no desde el superior y el inferior en este sentido, la iglesia institución, acomodada en estructuras que la sostienen, ha propiciado este tipo de relación, que el Papa Francisco denuncia en EG y propone una conversión a Jesús Buen Pastor. El sacerdote es servidor de los demás, "tiene olor a oveja" es decir es uno más del rebaño.

La iglesia, pueblo peregrino, no puede encerrarse en estructuras de una institución sacramental, como una oficina, su oferta es espiritual, es el Dios vivo que se hace carne en la vida de las personas, y en ese parto está María...

¿Podemos afirmar que la religiosidad popular puede ser un movimiento peligroso, que es necesario mantener a raya? ¿A qué se teme? Todo indica que se teme al poder que tiene la fuerza vital fruto de una acción del Espíritu que no se puede medir, controlar y frente a ella solo aplica el silencio, la contemplación y una interpretación certera de su simbología. ¿Qué nos dice? Que la obra evangelizadora es de Dios, que nos sorprende con su misterio revelado a los pobres y sencillos pues es un "Deus semper maior."

La religiosidad popular ha roto paradigmas, por eso ha sido una piedra en el zapato para personas con esquemas mentales rígidos y apegadas a los dogmas, pues al contemplar las masas de personas que espontáneamente acuden a los santuarios a celebrar libremente su fe, sintiendo que cada uno es protagonista de esa celebración, es un fenómeno que nos invita a reflexionar cómo es la iglesia peregrina que vive hoy. 
El magisterio del Papa Francisco es una demostración de que el continente de la esperanza comienza a dar de su riqueza a la humanidad, esto nos enorgullece y nos hace valorar la riqueza del aporte de la teología del pueblo a la humanidad. Quedan muchos desafíos que Francisco enumera en EG para que la nueva evangelización no sea un barniz superficial sino que busca que todos se sientan sujetos activos en la tarea evangelizadora. La hermenéutica de las expresiones de fe popular, que desde el DP 469, se viene proponiendo, es un reto que implica la formación y capacitación de clérigos y agentes pastorales para discernir y acompañar los procesos de la gente. El pueblo seguirá viviendo su religiosidad con notoria autonomía y espontaneidad frente a las instancias institucionales de la Iglesia. Depende de nuestra actitud como la del Buen Pastor, con las características propuestas por Francisco EG 24, para que nuestra iglesia siga creciendo por atracción y no por proselitismo.

La Iglesia tendrá que iniciar a sus hermanos - sacerdotes, religiosos y laicos - en este « arte del acompañamiento », para que todos aprendan siempre a quitarse las sandalias ante la tierra sagrada del otro (cf. Ex3,5). Tenemos que darle a nuestro caminar el ritmo sanador de projimidad, con una mirada respetuosa y llena de compasión pero que al mismo tiempo sane, libere y aliente a madurar en la vida cristiana ${ }^{47}$.

Y en este camino que Francisco nos invita a recorrer, encontramos en María el testimonio de quien sabe reconocer las huellas del Espíritu de Dios en los grandes acontecimientos y también en aquellos que parecen imperceptibles.

\footnotetext{
${ }^{47}$ Cfr. EG 169.
} 